\title{
Тува превращается в моноэтничный регион: риски и перспективы ${ }^{1}$
}

И. С. ТАРБАСтАЕВА, ИНститут философии и права СО РАН, Новосибирск. E-mail: inna-tarbastaeva@yandex.ru

В статье поднимается проблема сокращения этнокультурного разнообразия в Республике Тыва. Приводятся данные, свидетельствующие о миграционном оттоке русского населения за пределы региона. Показано, что факторами, способствующими моноэтнизации республики, являются не только экономическая отсталость субъекта, но и неудовлетворительное социальное самочувствие русских, которые находятся в статусе этнического меньшинства. Делается вывод, что процесс моноэтнизации неблагоприятно отражается и на титульном этносе. В частности, сокращение межэтнического взаимодействия на профессиональной основе препятствует обогащению тувинцев навыками, необходимыми для эффективного ведения экономической деятельности в современных условиях. Региональные власти оценивают сложившуюся ситуацию как неблагоприятную и принимают нестандартные решения для ее исправления. К позитивным факторам отнесены чувство гордости тувинцев за сохранение традиционной культуры, возможности развития этноэкономики.

Ключевые слова: моноэтнизация, сокращение этнокультурного многообразия, миграция русских, межэтнические отношения, русский язык, традиционная культура

В настоящее время наблюдается тенденция к сокращению количества этнических групп, проживающих на территории Республики Тыва. Несмотря на то, что исторически на данной территории проживали тувинцы, в советский период, благодаря политике распределения, в республику направлялись русскоязычные специалисты, преимущество русские. В кризисные 1990-е годы увеличилась миграция русского населения в соседние регионы, что повлекло за собой качественное изменение этнической структуры данного сообщества в сторону моноэтничной среды. Этот процесс усугубляется и транспортной труднодоступностью: отсутствие железной дороги изолирует республику от остальной части России. По сути, Тува - единственный субъект в Сибири с доминирующим преобладанием титульной группы населения

${ }^{1}$ Работа выполнена в рамках раздела «Этнокультурные механизмы пространственного развития Сибири» междисциплинарного проекта «Экономико-географические, этнокультурные и историко-демографические механизмы пространственного развития Сибири» Комплексной программы фундаментальных научных исследований СО РАН II.1. 
(86\%). Для нас важно не только зафиксировать проблему существенного понижения степени полиэтничности, но и постараться дать ей объяснение, в особенности раскрыть факторы, способствующие «сжатию» русского населения в республике.

\section{Моноэтнизация как тенденция}

Любое локальное сообщество представляет собой совместное проживание людей с различными этнокультурными, религиозными, ценностными установками, и в этом смысле его можно назвать межэтническим. Однако численное соотношение этнических групп в каждом регионе разное, и этот факт в значительной степени влияет на этносоциальные процессы, протекающие в нем. Моноэтничность как этносоциальная характеристика региона как раз показывает пропорциональное распределение тех или иных национальностей на конкретной территории. Однако необходимо учитывать не только количественные показатели, но и исторические особенности формирования сообщества, динамику изменения этнической структуры населения, государственно-территориальный статус субъекта, а также то, является ли он внутренним или трансграничным регионом. Кроме того, важно, какие именно этнические группы являются доминирующими, а какие - в меньшинстве.

Исследовательский интерес вызывает скорее не факт моноэтничности региона, а моноэтнизация как развивающийся во времени и пространстве процесс, сопровождающийся качественными изменениями в этнической структуре населения и имеющий неблагоприятные последствия для данного локального сообщества. Такие субъекты нуждаются в социокультурном мониторинге с привлечением экспертов. Особое внимание следует уделять республикам, поскольку в них сконцентрированы основные народы, традиционно проживающие в России, и благоприятные межэтнические взаимоотношения в данных регионах влияют на общегосударственную национальную политику. Позитивное взаимодействие между русскими и другими народами, проживающими на территории Российской Федерации, составляет основу межнациональной стабильности. Пограничный статус республик и вытекающие отсюда интересы государственной безопасности накладывают еще большую ответственность за спокойную бесконфликтную обстановку внутри региона.
В России большинство регионов являются моноэтничными с преобладающей долей русского населения (72 субъекта из 85). В национальных республиках доля государствообразующих этносов в значительной степени различается (табл. 1). Только в Карелии $(78,9 \%)$ и Хакасии $(80,3 \%)$ они составляют абсолютное большинство. Минимальное количество русских зафиксировано в Туве (16,1\%), Дагестане (3,6\%), Чечне (1,9\%), Ингушетии (0,8\%). В данных республиках наблюдается процесс территориальной концентрации титульных групп и снижения полиэтничности за счет сокращения русского населения. Аналогичные процессы зафиксированы в Татарстане и Северной Осетии [Орлов, 2013].

Таблица 1. Удельный вес русского населения в республиках по переписи 2010 г., \%²

\begin{tabular}{|l|c|l|c|}
\hline \multicolumn{1}{|c|}{ Республика } & Доля русских & \multicolumn{1}{c|}{ Республика } & Доля русских \\
\hline Хакасия & 80,3 & Башкортостан & 35,1 \\
\hline Карелия & 78,9 & Карачаево-Черкесия & 31,4 \\
\hline Бурятия & 64,9 & Калмыкия & 29,6 \\
\hline Коми & 61,7 & Чувашия & 25,8 \\
\hline Адыгея & 61,5 & Кабардино-Балкария & 22,5 \\
\hline Удмуртия & 60,0 & Северная Осетия & 20,6 \\
\hline Алтай & 55,7 & Тува & 16,1 \\
\hline Мордовия & 53,2 & Дагестан & 3,6 \\
\hline Марий Эл & 45,1 & Чечня & 1,9 \\
\hline Татарстан & 39,0 & Ингушетия & 0,8 \\
\hline Якутия & 36,9 & & \\
\hline & & &
\end{tabular}

\section{Сокращение этнокультурного многообразия}

На территории современной Тувы с XVII в. проживали тувинские племена, которые не подвергались интенсивным ассимиляционным процессам. Несмотря на межкультурное взаимодействие, в данном локальном сообществе тувинцы всегда составляли большинство. Доля представителей других

${ }^{2}$ Всероссийская перепись населения. 2010. Т. 4. Национальный состав и владение русским языком, гражданство. Население по национальности и владению русским языком по субъектам Российской Федерации. URL: http://www.gks.ru/free doc/new site/ perepis2010/croc/perepis_itogi1612.htm (дата обращения: 15.03.2018); Всероссийская перепись населения 2002 года. Национальный состав и владение русским языком, гражданство. Население по национальности и владению русским языком по субъектам Российской Федерации. URL: http://www.perepis2002.ru/index.html?id=17 (дата обращения: 15.03.2018). 
национальностей в разные годы менялась, но само сообщество было этнически однородным. По сути, Тува никогда не была полиэтничным регионом. Тем не менее современная этническая структура населения свидетельствует о значительном понижении существующего этнокультурного многообразия, образовавшегося в результате советской национальной политики. Выделим четыре основные характеристики, в наибольшей степени отражающие специфику моноэтнизации региона.

Bo-nервых, в Туве сократилось количество этнических групп. Если в 2002 г. в республике проживало 103 представителя различных национальностей, то в 2010 г. $-84^{3}$. Такое незначительное понижение само по себе не является поводом для тревоги, но весьма показательно в контексте общей динамики. В соседних республиках ситуация примерно такая же: в республиках Алтай, Хакасия в 2002 г. было зафиксировано 95 и 118 представителей других национальностей, в 2010 г. - 80 и 107.

Bo-вmopblx, в значительной степени сократился удельный вес представителей различных национальностей. Численность некоторых народов (белорусы, казахи, азербайджанцы) с 2002 г. снизилась практически вдвое (табл. 2).

Наиболее высокая степень полиэтничности в республике зафиксирована всесоюзной переписью 1989 г. К многочисленным национальностям в тот период, помимо двух основных этнических групп - тувинцев и русских, относились хакасы, украинцы, татары. Эти народы, отличающиеся от титульного этноса по своим культурным особенностям и религии, привносили национальный колорит в жизнь республики, быт и досуг населения. Начало процессу обеднения этнокультурной палитры было положено в кризисные 1990-е годы, и до настоящего временя сохраняется тенденция к уменьшению удельного веса представителей данных национальностей. Так, в регионе не осталось этнической группы, кроме русских, численность которых превысила бы тысячу человек. Третьей по численности группой являются хакасы (877 чел.).

${ }^{3}$ Всероссийская перепись населения. 2010. Т. 4. Национальный состав и владение русским языком, гражданство. Население по национальности и владению русским языком по субъектам Российской Федерации. URL: http://www.gks.ru/free_doc/new_site/ perepis2010/croc/perepis itogi1612.htm (дата обращения: 15.03.2018);
Таблица 2. Национальный состав населения Республики Тыва по данным переписей 1959, 1989, 2002, 2010 гr. ${ }^{4}$

\begin{tabular}{|l|c|c|c|c|}
\hline \multicolumn{1}{|c|}{ Народ } & $\mathbf{1 9 5 9}$ & $\mathbf{1 9 8 9}$ & $\mathbf{2 0 0 2}$ & $\mathbf{2 0 1 0}$ \\
\hline Украинцы & 1105 & 2208 & 832 & 493 \\
\hline Мордва & 234 & 334 & 106 & 56 \\
\hline Татары & 481 & 1071 & 584 & 352 \\
\hline Буряты & 263 & 570 & 436 & 313 \\
\hline Башкиры & & 217 & 101 & 59 \\
\hline Хакасы & 1726 & 2258 & 1219 & 877 \\
\hline Узбеки & & 523 & 161 & 253 \\
\hline Киргизы & & 64 & 520 & 628 \\
\hline Армяне & & 299 & 500 & 512 \\
\hline Корейцы & & 117 & 188 & 162 \\
\hline
\end{tabular}

Вместе с тем наблюдается увеличение числа представителей отдельных национальностей. Так, армян, киргизов по сравнению с 1989 г. стало вдвое больше (см. табл. 2). Однако острой проблемы, связанной с трудовыми миграционными потоками, в Туве нет. С точки зрения заработка республика непривлекательна для мигрантов, уступая соседним крупным развитым городам - Новосибирску, Красноярску.

$B$-третьих, в Туве за последние двадцать лет произошло значительное сокращение численности русского населения. По данным переписи, в 2010 г. доля русских составляла всего 16,3\%5. Это, пожалуй, одна из самых серьезных проблем для местной элиты и населения в целом, которая оказывает существенное влияние на экономическую, социальную, межнациональную сферы. А учитывая трансграничный статус республики, влияет и на геополитические интересы российского государства.

\footnotetext{
Всероссийская перепись населения. 2010. Т. 4. Национальный состав и владение русским языком, гражданство. Население по национальности и владению русским языком по субъектам Российской Федерации. URL: http://www.gks.ru/free doc/new_site/ perepis2010/croc/perepis_itogi1612.htm (дата обращения: 15.03.2018); Всесоюзная перепись населения 1959 года. Национальный состав населения по регионам России: Тувинская AO. URL: http://www.demoscope.ru/weekly/ssp/rus_nac_59.php (дата обращения: 15.03.2018); Всероссийская перепись населения 2002 года. Национальный состав и владение русским языком, гражданство. Население по национальности и владению русским языком по субъектам Российской Федерации. URL: http://www.perepis2002.ru/index. html?id=17 (дата обращения: 15.03.2018)

${ }^{5}$ Всероссийская перепись населения. 2010. Т. 4. Национальный состав и владение русским языком, гражданство. Население по национальности и владению русским языком по субъектам Российской Федерации. URL: http://www.gks.ru/free_doc/new_site/ perepis2010/croc/perepis_itogi1612.htm (дата обращения: 15.03.2018).
} 
Процесс «сжатия» русского населения наглядно демонстрируют данные переписи: 1959 г. - 68924 чел. (40,1\%), 1970 г. 88385 (38,3\%), 1979 г. -96793 (36,2\%), 1989 г. - 98831 (32\%), 2002 г. -61442 (20,1\%), 2010 г. - 49434 чел. (16,3\%) [Кан, 2016]. Таким образом, фактически русские в Туве находятся в статусе этнического меньшинства. Их территориальное распределение отличается неравномерностью и компактностью проживания. Основная часть сосредоточена в Кызыле, который до конца 1980-х гг. был «русским» городом. В 1970 г. их удельный вес в столице составлял $80 \%$, в 1979 г. $-74,6 \%$, в $1989-63,9 \%$, в 2002 г. $-36,5 \%{ }^{6}$. По данным переписи 2010 г., численность данной группы населения в столице республики сократилась на 7648 чел.; их доля - 28,4\% от общего числа жителей 7 .

Кроме того, немало русских проживают в центральных районах республики - Каа-Хемском, Кызылском, Пий-Хемском и Тандинском (рис. 1.). К сожалению, и там их присутствие заметно сокращается. По сравнению с переписью 2002 г. в Каа-Хемском кожууне русских стало меньше на 860 чел., в Кызылском на 632 чел., в Пий-Хемском - на 980 чел., в Тандинском - на 711 чел. [Моллеров, 1989]. В Улуг-Хемском кожууне и г. Ак-Довурак русское население в этнической структуре также представлено: 1345 и 573 человека соответственно. В остальных же административных районах их численность незначительна. К примеру, на 2010 г. в Овюрском кожууне проживало 69 чел., в то время как тувинцев насчитывалось 6890 человек. В Мон-Тайгинском кожууне зафиксирована аналогичная ситуация: 12 русских и 5608 тувинцев. Таким образом, из семнадцати районов республики одиннадцать являются мононациональными (рисунок) ${ }^{8}$.

${ }^{6}$ Балакина Г.Ф. Особенности и динамика структуры населения Республики Тыва URL: http://ipc-publisher.ru/admin/files/2013/1/sb(191-196(BalakinaGF.pdf (дата обращения: 15.03.2018).

Всероссийская перепись населения. 2010. Т. 4. Национальный состав и владение русским языком, гражданство. Население по национальности и владению русским языком по субъектам Российской Федерации. URL: http://www.gks.ru/free doc/new site/ perepis2010/croc/perepis itogi1612.htm (дата обращения: 15.03.2018).

${ }^{8}$ Национальный состав Республики Тыва. Управление федеральной службы государственной статистики по Красноярскому краю, Республике Хакасия и Республике Тыва. http://krasstat.gks.ru/wps/wcm/connect/rosstat_ts/krasstat/resources/e89b5d004233 ca31a33cef2d59c15b71/\%D0\%A $1 \% \mathrm{D} 1 \% 82 \% \mathrm{D} 0 \% \mathrm{~B} 0 \% \mathrm{D} 1 \% 82 \% \mathrm{D} 1 \% 8 \mathrm{C} \% \mathrm{D} 1 \% 8 \mathrm{~F} . \mathrm{htm}$ (дата обращения: 15.03.2018).

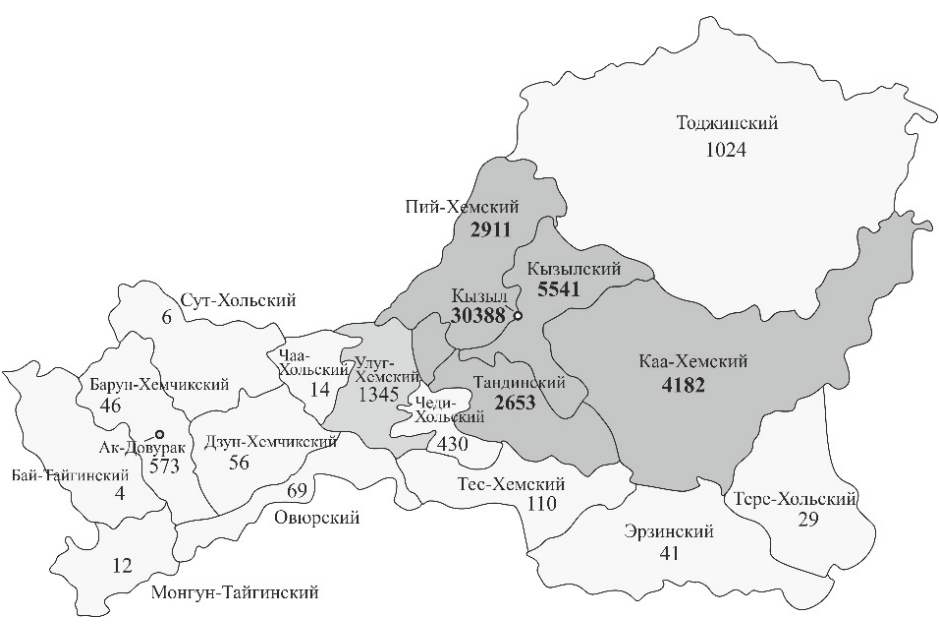

Численность русских в муниципальных районах Республики Тыва (по данным переписи 2010 г.), чел.

$B$-четвертых, существует тенденция к увеличению численности тувинцев за счет естественного прироста: только с 2002 г. по 2010 г. их стало на 20492 чел. больше. А за вторую половину XX века данная этническая группа увеличилась в 2,5 раза: с 97996 до 249299 чел. [Кан, 2016]. Среди тувинцев сохраняется традиционно высокий престиж материнства и многодетности. Поэтому республика показывает высокий коэффициент рождаемости, в основном за счет отдаленных и труднодоступных сельских районов - Тере-Хольского, Монгун-Тайгинского ${ }^{9}$. Среди российских регионов Тува на протяжении нескольких лет является одним из лидеров по демографическому приросту населения (наряду с Чечней и Ингушетией ${ }^{10}$ ).

Таким образом, специфика этносоциальной ситуации такова: сжатие русского населения с одновременным увеличением численности тувинцев при незначительной доле других

9 Тува по итогам 2014 года стала лидером России по естественному приросту населения. URL: http://gov.tuva.ru/press_center/news/society/14639/ (дата обращения: 15.03.2018).

${ }_{10}$ Рейтинг рождаемости - 2017: 10 благополучных регионов. URL: http://www. vestifinance.ru/articles/94424?page=1 (дата обращения: 15.03.2018). 
национальностей в этнической структуре сообщества. Такая тенденция неизбежно приводит к моноэтнизации региона. Этносоциологи отмечают, что доля русского населения за последние три десятилетия устойчиво снижалась и в отдельных республиках Сибири: Алтай - с 63,2 до 56,6\%, Бурятия - с 72,0 до $66,1 \%$, Саха (Якутия) - с 50,4 до 37,8\% [Попков, 2013].

\section{Взаимодействие русских и тувинцев: исторический контекст}

Проблему сокращения русского населения в данном локальном сообществе следует рассматривать в исторической перспективе. Взаимодействие между двумя этническими группами датируется началом XX века. В этот период происходит стихийное переселение недовольных властью русских крестьян из Енисейской губернии в Урянхайский край (прежнее название Тувы). Они проживали там довольно компактно, построив первые на данной территории поселки. Такое автономное проживание даже было официально оформлено в виде Русской самоуправляющейся трудовой колонии (1921-1932 гг.). По данным 1925 г., она объединяла до 12 тыс. русских жителей [Моллеров, 1989]. Но хотя совместное проживание двух народов протекало мирно, активного взаимопроникновения культур и плотного взаимодействия не происходило. Существовала значительная дистанция в менталитете, образе жизни, религиозных воззрениях. Русские исповедовали православие, тувинцы - шаманизм, буддизм. Крестьяне жили в поселках, тувинцы продолжали кочевать с зимних на летние пастбища; переход на оседлый образ жизни произошел только в 1950 г. [Самарина. 2011].

После добровольного присоединения в 1944 г. к Советскому Союзу в Туву направляются высококвалифицированные специалисты из различных регионов страны. Удельный вес русского населения в отдельных районах республики значительно увеличился. Так, в Каа-Хемском кожууне в 1970 г. он составлял 63\%, 1979 г. $-39,1 \%, 1989$ г. - 48,1\% ${ }^{11}$. В этот период приезжим предоставлялись социальные привилегии в виде бесплатного

${ }^{11}$ Балакина Г. Ф. Особенности и динамика структуры населения Республики Тыва. URL: http://ipc-publisher.ru/admin/files/2013/1/sb(191-196(BalakinaGF.pdf (дата обращения: 15.03.2018). жилья, престижных рабочих мест, в то время как основная часть тувинского населения не имела высшего образования, слабо владела русским языком. Кроме того, проводилась откровенная политика подавления и нивелирования любых проявлений тувинской культуры, традиций, обычаев [Кужугет, 2010]. Все традиционное воспринималось скорее как некое «докультурное» состояние, целина, которую нужно «поднимать». Коренное население такое отношение расценивало как высокомерие и стало стремиться к закрытости ${ }^{12}$. Все это порождало отчуждение двух этнических групп.

В 1996 г. известный социолог Л. М. Дробижева писала: «Величина объективной психологической дистанции между тувинцами и русскими Тувы по крайней мере в два раза больше любого из аналогичных показателей, полученных нами». Она отмечала, что это - результат советского периода, когда резкий прирост русского населения, сопровождающийся более привилегированным его положением по сравнению с тувинцами, не способствовал этнокультурному сближению [1996. С. 323]. Промахи советской национальной политики стали почвой для обострения межнациональных отношений, что в конечном итоге привело к конфликту между русскими и тувинцами в начале 1990-х годов. Это был переломный момент во взаимоотношениях, который положил начало миграционному оттоку русского населения. Социологи делают неутешительные прогнозы: к переписи 2020 г. доля русских в этнической структуре населения будет в пределах 8-10\% [Кан, 2016].

\section{Почему русские уезжают из Тувы}

Почему же русские покидают республику? Местная элита пытается объяснить этот процесс исключительно неблагоприятной социально-экономической ситуацией. В одном из интервью глава субъекта Шолбан Кара-оол выразил эту позицию следующим образом: «Рыба ищет, где глубже, а человек-где лучше. Что значит лучше? В понимании современного россиянина, лучше там, где доходы населения посолиднее, где дешевле жилье, электроэнергия, бензин, продовольственные товары, а качество

\footnotetext{
${ }^{12}$ Мышлявщев Б. А. Нормативная культура тувинцев (конец XX - начало XXI в.) [Эл. pecypc] // Samlib.ru. URL: http://samlib.ru/m/myshljawcew boris aleksandrowich/tuva-1. shtml (дата обращения: 15.03.2018)
} 
образования, медицинского обслужсивания - выше. И по этим параметрам мы пока проигрываем даже соседям... О мотивации оттока русскоязычного населения можно говорить ещче долго, но главная причина...-качество жизни» ${ }^{13}$. Действительно, республика относится к проблемным регионам, отстающим в экономическом развитии. Чрезмерно низкие душевые доходы населения, недостаточный производительный и финансовый потенциал, высокая дотационность делают ее «аутсайдером», периферийным субъектом с точки зрения привлекательности проживания. Однако существуют и иные факторы, влияющие на сокращение удельного веса русского населения. Поскольку в экономическом плане именно русские в Туве, благодаря владению профессиональными навыками в индустриальной сфере, высокому уровню образования, оказались в более выгодных условиях, чем титульное население, они не испытывают трудностей с удовлетворением основных жизненных потребностей. Но их социальное самочувствие вызывает серьезные опасения: они испытывают большой психологический дискомфорт, меньше уверены в достижении успеха.

Региональные исследователи неоднократно поднимали эту проблему; в большинстве своем ученые, эксперты дают похожие оценки. Так, 3.В. Анайбан, Г.Ф. Балакина пишут, что положение русскоязычного населения Тувы изменилось: теперь за ними закрепилась роль не «старшего брата», а представителей национального меньшинства, имеющих более низкий уровень возможностей и более выраженные миграционные устремления [Балакина, Кылгылдай, 2016]. По словам А. К. Кужугет, в регионе уже давно проявляется понижение социального, политического статуса русских. У русских возрастает чувство национальной неполноценности. Они оттеснены на периферию жизни и вынуждены покидать республику, даже если полюбили ее, прожив здесь много лет [2010].

Важно отметить, что серьезных конфликтов на межнациональной почве не наблюдается. Однако полноценное выражение русской этнической идентичности зачастую сталкивается с неприятием ее доминирующим большинством, в особенности

${ }^{13}$ Глава Тувы Шолбан Кара-оол дал откровенное интервью на тему межнациональных отношений. Официальный портал Республики Тыва. 2015. URL: http://gov.tuva.ru/ press_center/news/society/21757/ (дата обращения: 15.03.2018). в районах республики, где русское население практически отсутствует. Инаковость в таком моноэтничном пространстве воспринимается как чужеродная, вызывая не столько агрессивное отталкивание, сколько нежелание контактировать на тех же основаниях, что и с представителями своей этнической группы. Стремление к бесконфликтному проживанию в этих районах вынуждает людей пойти на некоторый внутренний отказ от русской ментальности в пользу тувинской. Все это приводит к быстрому сжатию русского населения.

Наиболее типичный сценарий отъезда русскоязычного населения таков: дети поступают в высшие учебные заведения в другом регионе, трудоустраиваются, затем родители, продав недвижимость, переезжают к ним. Русская молодежь легко адаптируется в крупных городах, во время студенчества практически не посещает мероприятия землячества. В большинстве своем она стремится закрепиться на новом месте и не возвращаться в республику. Хотя все это не исключает теплые чувства к малой Родине и личную дружбу с тувинской молодежью. До окончания процесса обучения родители, как правило, продолжают работать, чтобы иметь возможность поддерживать студентов материально. Кроме того, представители старшего поколения предпочитают дорабатывать на прежнем месте до наступления пенсионного возраста, прежде чем решиться на переезд в другой регион. В целом русские более конкурентоспособны на рынке труда; это позволяет им выбирать альтернативные жизненные стратегии.

Тувинцы же из-за слабого владения русским языком, национального менталитета больше приспособлены к проживанию в пределах региона. Тем не менее их миграционная активность также возрастает (табл. 3). Так, с 2002 по 2010 гг. в Красноярском крае, Новосибирской области, республиках Хакасия и Бурятия численность тувинцев увеличилась в два раза. В основном это молодые люди, обучающиеся в высших или средних заведениях; реже - выехавшие на заработки. Тенденция к получению высшего образования усиливается, поэтому мобильность тувинской молодежи, а следовательно, и ее удельный вес в российских регионах будут возрастать. 
Таблица 3. Численность тувинцев в регионах Российской Федерации в 2002-2010 гг. ${ }^{14}$

\begin{tabular}{|l|c|c|}
\hline \multicolumn{1}{|c|}{ Регион } & $\mathbf{2 0 0 2}$ & $\mathbf{2 0 1 0}$ \\
\hline Красноярский край & 1492 & 2939 \\
\hline Иркутская область & 513 & 1674 \\
\hline Новосибирская область & 526 & 1252 \\
\hline Томская область & 197 & 983 \\
\hline Хакасия & 494 & 936 \\
\hline Бурятия & 405 & 909 \\
\hline Москва & 415 & 682 \\
\hline Санкт-Петербург & 272 & 461 \\
\hline Свердловская область & 145 & 155 \\
\hline Хабаровский край & 334 & 398 \\
\hline Республика Алтай & 22 & 158 \\
\hline
\end{tabular}

Важно отметить: если русские уезжают на постоянное место проживания, то тувинцы ориентированы на временное. В мировоззрении последних Тува является «родной землей», «домом», тем местом, где тувинец чувствует себя психологически комфортно. Несмотря на неудовлетворительные показатели качества жизни в сравнении с другими регионами, они не стремятся покинуть родную республику, а предпочитают жить и работать среди представителей своей этнической группы.

\section{Последствия моноэтнизации Тувы}

Сокращение русского населения в регионе неблагоприятно отразилось на социальной, экономической, культурной сферах общественной жизни. Прежде всего, серьезные проблемы возникли с функционированием русского языка: сузилась его коммуникативная среда, уменьшились разговорные практики у титульного населения республики. Сельские жители отдаленных районов достаточно слабо владеют русским языком, в особенности молодое поколение. Отсюда вытекают трудности

${ }_{14}^{14}$ Всероссийская перепись населения. 2010. Т. 4. Национальный состав и владение русским языком, гражданство. Население по национальности и владению русским языком по субъектам Российской Федерации. URL: http://www.gks.ru/free doc/new site/ perepis2010/croc/perepis_itogi1612.htm (дата обращения: 15.03.2018); Всероссийская перепись населения 2002 года. Национальный состав и владение русским языком, гражданство. Население по национальности и владению русским языком по субъектам Российской Федерации. URL: http://www.perepis2002.ru/index.html?id=17 (дата обращения: 15.03.2018). с доступом к качественному образованию, интеграцией в российское социокультурное пространство. Так, глава региона Шолбан Кара-оол заявил: «Не секрет, что сегодня именно из-за неважного, прямо скажем, владения русским наши ребятишки очень часто проваливаются при поступлении в вузы или отсеиваются на начальных курсах, и эта проблема давно переросла масштаб их личной трагедии. Она уже давно и очень больно бьет по всей республике» ${ }^{15}$. По его инициативе было сформировано два специализированных института. Первый - это лаборатория проблем преподавания русского языка при Министерстве образования и науки Республики Тыва в рамках Института развития национальной школы. Второй - введена должность государственного инспектора по русскому языку. Тува - единственный регион в России, где официально существует такая должность. Внимание со стороны региональных властей к государственному языку повышает престиж той категории населения, для которого он является родным, а также способствует выравниванию положения русского населения в сфере распределения социальных благ.

Еще одна проблема, связанная с оттоком русского населения из республики, заключается в том, что регион потерял достаточное количество высококвалифицированных кадров, которые трудились на высокотехнологичных предприятиях. В частности, в 2000-х годах серьезно пострадал горнодобывающий комплекс, из-за чего руководство предприняло меры по сворачиванию мощностей производства [Ойдуп, 2006]. Индустриализация тувинского хозяйства в советские годы с направлением русских специалистов, несмотря на идеологические перегибы, позволила местному населению обогатить свои социальные практики. Благодаря повседневному межэтническому взаимодействию на профессиональной основе тувинцы обретали навыки, необходимые для адаптации к социокультурным переменам. В настоящее время в республике отсутствует основа для широких контактов тувинцев с представителями других национальностей. Практически коренное население остается «наедине с собой», что существенно тормозит развитие креативного мышления, необходимого для

${ }^{15}$ В Туве в Год русского языка родились инициативы, достойные продолжения Шолбан Кара-оол. [Эл. ресурс] // Официальный портал Республики Тыва. URL: http://gov. tuva.ru/press center/news/ education/11607/ (дата обращения: 15.03.2018). 
новых стандартов экономической деятельности. Если не предпринять меры по кардинальному изменению ситуации, то в будущем титульному населению практически не у кого будет перенимать иные подходы к ведению экономики.

Вместе с тем моноэтнизации нельзя давать исключительно отрицательную оценку. Компактное проживание этноса позволяет в большей степени сохранить его культурную самобытность. В таком коллективном образовании аккумулируются наиболее значимые традиционные установки, социальные практики, которые в дальнейшем воспроизводятся на индивидуальном уровне. Действительно, тувинцы довольно успешно поддерживают национальные традиции; это придает им чувство уверенности, гордости за свою республику. Родной язык, кочевой образ жизни, шаманизм, буддизм, священные обряды, горловое пение, национальная борьба хуреш, - все это не только визитные карточки региона, но и повседневные социальные практики народа. Гости республики часто отмечают, что Тува отличается от других регионов своим национальным колоритом, ритмом и укладом жизни. Учитывая это, местные власти пытаются развивать туристическую привлекательность, формировать соответствующую инфраструктуру, профессиональные кадры.

В моноэтничных регионах также могут весьма успешно реализовываться проекты, связанные с традиционным хозяйствованием народа. В последние годы отмечается развитие животноводческого комплекса, растет спрос на экологически чистую тувинскую продукцию. Местные производители успешно поставляют на внутренний рынок мясные, молочные продукты; существует даже конкуренция среди фирм. В Кызыле работают несколько сельскохозяйственных рынков, созданных специально для поддержки данной категории предпринимателей. Следует отметить, что жители республики с удовольствием покупают тувинскую продукцию, отдавая предпочтение именно ей.

$$
\text { *** }
$$

Серьезных изменений в этнической структуре Тувы в ближайшие годы не предвидится. Динамика миграционного оттока русских за пределы региона останется положительной. Вероятно также снижение удельного веса других национальностей в общей численности населения. Факторов, способствующих моноэтнизации, достаточно много: транспортная труднодоступность республики, низкое качество жизни, высокий уровень бытовой преступности, неудовлетворительное социальное самочувствие людей, находящихся в статусе этнического меньшинства. Сложившая ситуация неблагоприятным образом отражается и на титульном этносе.

\section{Литература}

Балакина Г.Ф., Кылгыдай А. Ч. Особенности адаптации этнических групп Тувы к рыночной экономике // Новые исследования Тувы. 2016. № 2 (30). URL: https://cyberleninka.ru/article/n/osobennosti-adaptatsii-etnicheskih-grupp-tuvy-krynochnoy-ekonomike (дата обращения: 15.03.2018).

Демократизация и образы национализма в РФ 90-х годов. / Л.М. Дробижева, А.Р. Аклаев, В.В. Коротеева, Г.У. Солдатова. РАН. Ин-т этнологии и антропологии. М., 1996. 282 с.

Кан В.С. Этносоциальный профиль тувинцев [Эл. ресурс] // Новые исследования Тувы. 2016. № 2. URL: http:/nit.tuva.asia/nit/ article/view/94 (дата обращения: 10.08.2016)

Кужугет А.К. Тувинцы и русские в контексте изучения чувства национального достоинства (постановка проблемы) // Новые исследования Тувы. 2010. № 3 (7). URL: https://cyberleninka.ru/article/n/tuvintsy-i-russkie-v-konteksteizucheniya-chuvstva-natsionalnogo-dostoinstva-postanovka-problemy (дата обращения: 15.03.2018).

Моллеров Н.М. Истоки братства. Русская самоуправляющаяся трудовая колония в Тувинской Народной Республике. Кызыл, 1989.

Ойдуn T.M. Горнодобывающий комплекс Тывы и будущее республики // ЭКО. 2006. № 10. С. 111-116.

Орлов А. Ю. Историко-географические аспекты трансформации этнической структуры населения Российской Федерации // Региональные исследования 2013. № 2. C. 120-124.

Попков Ю.В. Этносоциальные процессы и этнонациональная политика // Новые исследования Тувы. 2013. № 1 (17). URL: https://cyberleninka.ru/ article/n/etnosotsialnye-protsessy-i-etnonatsionalnaya-politika-1 (дата обращения: 15.03.2018).

Самарина Н.Г. Кочевое скотоводство и оседлость тувинцев в советский период // Вестн. Том. гос. ун-та. История. 2011. № 4 (16). URL: https://cyberleninka. $\mathrm{ru} /$ article/n/kochevoe-skotovodstvo-i-osedlost-tuvintsev-v-sovetskiy-period (дата обращения: 15.03.2018)

Статья поступила 06.04.2018.

\section{Summary}

Tarbastaeva I.S., Institute of Philosophy and Law, SB RAS, Novosibirsk

Tuva Turns to the Monothern Region: Risks and Prospects

The article raises the problem of reducing ethno-cultural diversity in the Republic of Tyva. Data are given that attest to the migration outflow of the Russian population 
outside the region. It is shown that the factors contributing to the monoetinization of the republic include the economic backwardness of the subject, the unsatisfactory social state of the Russians who are in the status of an ethnic minority. It is concluded that monoetanization has an unfavorable effect on the titular ethnos. In particular, the reduction of interethnic cooperation on a professional basis hinders the enrichment of Tuva residents with the skills necessary for the effective conduct of economic activity in modern conditions. Regional authorities recognize the current situation as unfavorable, and take non-standard solutions for its correction. Positive factors include the feeling of pride of Tuvinians for preserving traditional culture, the possibility of developing ethnoeconomics.

Monoetenization; reduction of ethnocultural diversity; migration of Russians; interethnic relations; Russian language; traditional culture

\section{References}

Balakina G.F., Kylgydai A. Ch. (2016) Osobennosti adaptatsii ehtnicheskih grupp Tuvy k rynochnoi ehkonomike. Novye issledovaniya Tuvy. No. 2. (In Russ) Available at: https://nit.tuva.asia/nit/article/view/95 (accessed: 25. 05.2017).

Demokratizatsiya i obrazy natsionalizma v Russian Federation 90-h godov (1996). L. M. Drobizheva, A. R. Aklaev, V.V. Koroteeva, G. U. Soldatova. Institute of Ethnology and Anthropology. Moscow, 282 p. (In Russ.)

Kan V.S. (2016) Ethnosocial profile of Tuvinians. Novye issledovaniya Tuvy. No. 2. (In Russ). Available at: http://nit.tuva.asia/nit/article/view/94 (accessed: 25. 05.2017).

Kuzhuget A.K. (2010) Tuvintsy i russkie v kontekste izucheniya chuvstva natsional'nogo dostoinstva (postanovka problemy). Novye issledovaniya Tuvy. No. 3. (In Russ). Available at: http://www.tuva.asia/journal/issue_7/2121-kujuget. html (accessed: 25. 05.2017).

Mollerov N.M. (1989) Istoki bratstva. Russkaya samoupravlyayushchayasya trudovaya koloniya v Tuvinskoj Narodnoj Respublike. Kyzyl. (In Russ.).

Oidup T.M. (2006) Gornodobyvayushchij kompleks Tyvy i budushchee respubliki. EKO [ECO]. No. 10. Pp. 111-116. (In Russ.)

Orlov A. Yu. (2013) Historical and geographical aspects of the transformation of the ethnic structure of the population of the Russian Federation. Regional'nye issledovaniya. [Regional research]. No. 2. Pp. 120-124. (In Russ.)

Popkov Yu. V. (2013) Ehtnosocial'nye processy i ehtnonatsional'naya politika. Novye issledovaniya Tuvy. No. 1 (17). (In Russ.). Available at: https://cyberleninka. $\mathrm{ru} /$ article/n/etnosotsialnye-protsessy-i-etnonatsionalnaya-politika-1 (accessed: 15.03.2018).

Samarina N. G. (2011) Kochevoe skotovodstvo i osedlost' tuvintsev v sovetskii period Vestnik of Tomsk State Univertsity. Series: History. [Bulletin of Tomsk State University. History]. No. 4 (16), Pp. 123-126. (In Russ) 